\title{
Skilled delivery service utilization and its association with the establishment of Women's Health Development Army in Yeky district, South West Ethiopia: a multilevel analysis
}

\author{
Melese Girmaye Negero ${ }^{1 *}$, Yifru Berhan Mitike ${ }^{2}$, Abebaw Gebeyehu Worku³ and Tafesse Lamaro Abota ${ }^{4}$
}

\begin{abstract}
Background: Because of the unacceptably high maternal and perinatal morbidity and mortality, the government of Ethiopia has established health extension program with a community-based network involving health extension workers (HEWs) and a community level women organization which is known as "Women's Health Development Army" (WHDA). Currently, the HEWs and WHDA network is the approach preferred by the government to register pregnant women and encourage them to link in the healthcare system. However, its association with skilled delivery service utilization is not well known.
\end{abstract}

Methods: A community-based cross-sectional study was conducted from January to February 2015 . Within 380 clusters of WHDA, a total of 748 reproductive-age women who gave birth in 1 year preceding the study, were included using multistage sampling technique. The data were entered into EPI info version 7 statistical software and exported to STATA version 11 for analysis. Multilevel analysis technique was applied to check for an association of selected variables with a utilization of skilled delivery service.

Results: About 45\% of women have received skilled delivery care. A significant heterogeneity was observed between "Women's Health Development Teams (clusters)" for skilled delivery care service utilization which explains about $62 \%$ of the total variation. Individual-level predictors including urban residence [AOR (95\% Cl) 35.10 (4.62, 266.52)], previous exposure of complications [AOR (95\% Cl) $3.81(1.60,9.08)$ ], at least four ANC visits [AOR (95\% Cl) 7.44 $(1.48,37.42)$ and preference of skilled personnel [AOR $(95 \% \mathrm{CI}) 8.11(2.61,25.15)]$ were significantly associated with skilled delivery service use. Among cluster level variables, the distance of clusters within $2 \mathrm{~km}$ radius from the nearest health facility was significantly associated [AOR (95\% CI) $6.03(1.92,18.93)]$ with skilled delivery service utilization.

Conclusions: In this study, significant variation among clusters of WHDA was observed. Both individual and cluster level variables were identified to predict skilled delivery service utilization. Encouraging women to have frequent ANC visits ( -4 and above), enhancing awareness creation towards the delivery care attendance, constructing more health facilities and roads in hard to reach areas and establishing telemedicine services are recommended.

Keywords: Community-based, Ethiopia, Multilevel analysis, Skilled delivery care, Women's Health Development Army

\section{Background}

As World Health Organization (WHO) defined, skilled care at delivery is a delivery service provided by "an

\footnotetext{
*Correspondence: melesegirmaye@gmail.com

1 Department of Public Health, College of Medical and Health Sciences, Wollega University, Nekemte, Ethiopia

Full list of author information is available at the end of the article
}

accredited health professional such as a midwife, doctor or other nurse-who have been educated and trained to proficiency in the skills needed to manage normal (uncomplicated) pregnancies, childbirth and the immediate postnatal period, and in the identification, management and referral of complications in women and newborns" [1-3]. An estimated 74\% of maternal deaths 
could be prevented if all women had access to skilled delivery and emergency obstetric care services [4-6]. Despite the existence of proven interventions to prevent disability or death during pregnancy and childbirth; maternal and perinatal mortality still remains to be major public health problems among sub-Saharan African countries, including Ethiopia [2, 6-11]. The WHO has estimated that 289,000 women died during pregnancy and childbirth in 2013 globally, a majority of which were in developing countries with limited access to skilled maternity services [12, 13]. According to Ethiopian Demographic and Health Survey (EDHS) 2011 and International Monetary Fund (IMF) consultation-staff report of 2014, the maternal mortality ratios in Ethiopia were $676 / 100,000$ and 420/100,000 live births, respectively, which are still among the highest in the world and sub-Saharan African Countries [14, 15]. Skilled personnel attended delivery care is a well known and proven intervention to reduce maternal and perinatal mortality and morbidity $[1,10,11,16-23]$. The unacceptably high maternal and perinatal mortalities in Ethiopia could probably be due to the very low coverage of skilled delivery care in the country. The EDHS 2011 and mini EDHS 2014 reported that only 10 and $15 \%$ of pregnant women in Ethiopia, respectively, received skilled delivery care which is among the lowest in the world and sub-Saharan African Countries [14, 24]. According to the-EDHS 2011, the reasons for not attending health facilities for delivery care were: "it was not important (61\%)", "not familiar (30\%)", and "health facilities were geographically inaccessible (14\%)", respectively, while the mini-EDHS 2014 revealed that similar reasons were given by 45,33 and $22 \%$, respectively of women who didn't give their last birth at health facilities [14, 24].

This indicates that lack of awareness, poor attitude, and inaccessibility of health facilities were the major factors for low coverage of skilled personnel attended delivery and hence high proportion of maternal and perinatal mortalities in Ethiopia.

To have effective community-based programs, the health extension program of Ethiopia involved community level women organization which is known as "Women's Health Development Army (WHDA)" Since 2011. The WHDA is Women's Health Development Team (WHDT) organized as one-to-five (about 5-6 members and one of them is the leader) and one-to-thirty (further grouping of the 6 sub-groups involving 30 members) of women in the nearby households. The one-to-thirty development team leaders are reporting the lists of pregnant women to the health extension worker (HEW) and the HEW send it to the Health Center (HC) regularly. At $\mathrm{HC}$, the expected date of delivery (EDD) of all listed pregnant women will be calculated and midwives try different mechanisms to trace based on their EDD [25, 26].

Currently, the HEWs and WHDA network is believed to be the best approach to implement health extension package (HEP) activities like enhancing women's seeking behavior in attending skilled maternity services [25, 26]. However, no or only little is known about the association of skilled delivery care service utilization with the establishment of this army. Therefore, this study was planned to assess skilled delivery care service utilization and associated factors at individual and WHDT levels in Yeky district, Southwest Ethiopia.

\section{Methods}

\section{Study design and setting}

A community-based cross-sectional study was conducted over 2 months (January-February 2015) among women of reproductive age who gave birth 1 year preceding the study at Yeky district, Sheka Zone, Southwest Ethiopia. The district is located about $562 \mathrm{~km}$ from the capital, Addis Ababa. It is structured into 22 rural "kebeles" (the lowest administrative units with a size of about 1000 households) and one town administration, Tepi town. Tepi is structured into three administrative kebeles. There are about 845 established and functioning WHDTs in the district, 632 in the rural kebeles and 213 in the district center, Tepi.

In 2014 , there were an estimated 172,520 people in Yeky district of which reproductive-aged women comprised 39,680. Majority of the inhabitants (96\%) are rural dwellers. Agriculture is the major means of livelihood. The district is also well known for its cash crops, like coffee and spices. The district has a total of 30 functioning public health institutions (22 Health posts, 7 health centers, and 1 district hospital). Local FM radios newly opened in the area are also playing some roles in creating awareness about the importance of delivering at health facilities.

\section{Study population and sampling}

Those women of reproductive age groups who gave birth in 1 year preceding the study in the randomly selected seven kebeles the in the study irrespective of their birth outcome. The sample size was calculated using single population proportion formula and Epi-Info version-7 statistical software based on the following assumptions: margin of error of $3 \%$, the design effect of 2 , non response rate of $10 \%$, a confidence level of $95 \%$, and proportion for skilled delivery service of 9.4\% [24]. Accordingly, the total sample size was 800 . We have tested the null hypothesis that there was no variation in skilled delivery care service utilization between clusters or WHDTs using multilevel analysis. 
Cluster sampling was applied to select the study population.

The kebeles with their WHDT (clusters) were selected randomly. Accordingly, 7 (5 rural and 2 urban) kebeles with a total of 380 WHDT were selected.

\section{Data collection and analysis}

A house to house interview was done using structured and pretested questioner. The questioners were employed to obtain information on socio-demographic, accessibility, perceived needs (benefits), and WHDT related characteristics. A total of 35 qualified data collectors and 14 supervisors ( 5 data collectors and 2 supervisors for each kebele) were deployed.

In this study, skilled delivery care service utilization refers utilization of delivery care service by mothers at a health center, hospital or private clinic for their last birth.

During analysis, performance of WHDTs was classified as best or grade "A" if all households have achieved 91-100\% of all the seventeen HEPs, including giving birth at health center, hospital or private clinics for eligible women, good or grade "B" if all households have achieved $81-90 \%$ of all the seventeen HEPs, and poor or " $C$ " if all households have achieved $<80 \%$ of all the seventeen HEPs.

Health extension package refers to a list of mainly preventive and promotive activities to be performed through the collaboration between HEWs and the local community $[25,26]$. It is categorized into four pillars of activities, namely family health, hygiene and sanitation, communicable disease control and health education and communication. Family health activities include immunization, family planning, maternal and child health care (e.g. skilled delivery utilization), preparation and utilization of balanced food and elimination of harmful traditional practices. Hygiene and sanitation activities include latrine construction and utilization, food hygiene, solid and liquid waste management, water sanitation, personal hygiene, home management and pest and vector control, while communicable disease control activities include prevention and control of malaria, HIV/AIDS and TBC. Providing first aid and integrated community case management of common childhood illnesses are also among the HEP activities [27, 28].

Similarly, self-sustained WHDT refers to availability of enough production (food or cash crops) for feeding population in the village (WHDT).

The data was entered using EPI Info version 7 statistical software and was exported to STATA version 11 for analysis. The predictors of skilled delivery care service utilization were assessed using the multilevel binary logistic regression analysis technique to measure individual and group-level (WHDT) variables.

\section{Results}

Socio-demographic and obstetric characteristics of the study participants

A total of 748 women aged 15-49 years participated in the study. The majority (84.5\%) were rural dwellers. Most $(95.6 \%)$ were currently married. The mean $( \pm$ SD) age of the participants was $25.8( \pm 5.3)$ where the majority $(32.9 \%)$ were between $25-29$ years category and 6.7\% were teenagers $(<20$ years). Nearly two-thirds $(62.3 \%)$ were Protestant Christians and about $92 \%$ were housewives. About $60 \%$ of the respondent's households had about 10 USD or less average monthly income while only $11 \%$ could get more than about 50 USD per month. Regarding the educational level, $45.7 \%$ didn't attend any formal education (Table 1).

Three hundred fifty $(46.8 \%)$ mothers were teenagers and $16(2.1 \%)$ were 35 and above years when they gave birth to their first baby. The mean $( \pm \mathrm{SD})$ age at the first birth was $19.9( \pm 2.6)$ years. The majority $(53.9 \%)$ of respondents had parity between $2-4$ births (Table 2).

\section{Delivery practice}

More than half (51.6\%) of respondents had given their last birth at home. Skilled delivery care was received by 334 (44.7\%) respondents for their recent birth. Regarding the birth attendants, 298 (39.8\%), 292 (39\%), 54 (7.2\%), 44 (5.9\%), $35(4.7 \%)$ and 25 (3.3\%) respondents were attended by their relatives, nurses, self (no one), doctor, health extension workers (HEWs) and traditional birth attendants for their last birth, respectively. Twenty-seven (3.6\%) respondents had delivered by cesarean section. Regarding their reasons for seeking health facility delivery, 322 (89\%), 296 (81.8\%), 194 (53.6\%), and 19 (2.5\%) respondents reported that it was for the maternal wellbeing, for the fetal wellbeing, to control bleeding and to prevent retained placenta, respectively.

For the respondents who did not give their last birth at health facilities, 238 (61.7\%), 55 (14.2\%) and 52 (13.5\%) respondents reported that it was because of easy labour, lack of transport and health facility was too far, respectively, while 42 (10.9\%), 18 (4.7\%) and 17 (2.3\%) respondents reported that it was because of lack of awareness, overnight labour, and birth delivered on the road to health facilities, respectively. Twelve (1.6\%) respondents reported that it was not accustomed to delivering at health facilities (Table 2).

\section{Multilevel (mixed effects) logistic regression analysis}

The multilevel analysis was started from the intercept only (null) model and then finalized on the random intercept model. The results depicted in Table 3 showed that there was significant heterogeneity between WHDTs with regard to skilled delivery service utilization. The 
Table 1 Selected socio-demographic individual-level characteristics of women who gave birth in 1 year preceding the study, Yeky district, 2015, ( $=748)$

\begin{tabular}{|c|c|c|}
\hline $\begin{array}{l}\text { Background character- } \\
\text { istics }\end{array}$ & Category & Number (\%) \\
\hline \multirow[t]{2}{*}{ Residence } & Urban & $116(15.5)$ \\
\hline & Rural & $632(84.5)$ \\
\hline \multirow[t]{5}{*}{ Current age in years } & $16-19$ & $50(6.7)$ \\
\hline & $20-24$ & $241(32.2)$ \\
\hline & $25-29$ & $246(32.9)$ \\
\hline & $30-34$ & $121(16.2)$ \\
\hline & $\geq 35$ & $90(12)$ \\
\hline \multirow[t]{9}{*}{ Ethnicity } & Keffa & $206(27.5)$ \\
\hline & Amhara & $143(19.1)$ \\
\hline & Bench & $134(17.9)$ \\
\hline & Sheka & $95(12.7)$ \\
\hline & Menja & $70(9.4)$ \\
\hline & Sheko & $34(4.5)$ \\
\hline & Mejengir & $18(2.4)$ \\
\hline & Dawuro & $18(2.4)$ \\
\hline & Others & $30(4)$ \\
\hline \multirow[t]{4}{*}{ Religion } & Protestant & $466(62.3)$ \\
\hline & Orthodox & $183(24.5)$ \\
\hline & Muslim & $92(12.3)$ \\
\hline & Others & $7(0.9)$ \\
\hline \multirow[t]{3}{*}{ Marital status } & Single & $18(2.4)$ \\
\hline & Married & $715(95.6)$ \\
\hline & Divorced & $15(2)$ \\
\hline \multirow{3}{*}{$\begin{array}{l}\text { Husband education } \\
\qquad(\mathrm{n}=715)\end{array}$} & No formal education & $188(26.3)$ \\
\hline & Primary education (1-8) & $451(63.1)$ \\
\hline & $\begin{array}{l}\text { Secondary education and } \\
\text { above }\end{array}$ & $76(10.6)$ \\
\hline \multirow{3}{*}{$\begin{array}{l}\text { Household monthly average } \\
\text { income in birr }\end{array}$} & $\leq 200$ & $448(59.9)$ \\
\hline & $201-1000$ & $217(29)$ \\
\hline & $>1000$ & $83(11.1)$ \\
\hline \multirow{2}{*}{$\begin{array}{l}\text { Who usually makes deci- } \\
\text { sions on the mother's } \\
\text { healthcare? (Autonomy) }\end{array}$} & Woman \pm husband & $251(33.6)$ \\
\hline & Husband \pm others & $497(66.4)$ \\
\hline \multirow{3}{*}{$\begin{array}{l}\text { Age when married first in } \\
\text { years }(n=736)\end{array}$} & $\leq 15$ & $137(18.6)$ \\
\hline & $16-19$ & $420(57.1)$ \\
\hline & $\geq 20$ & $179(24.3)$ \\
\hline \multirow[t]{3}{*}{ Parity } & 1 & $224(29.9)$ \\
\hline & $2-4$ & $403(53.9)$ \\
\hline & 5 and above & $121(16.2)$ \\
\hline \multirow[t]{3}{*}{ Maternal education } & No formal education & $342(45.7)$ \\
\hline & Primary education (1-8) & $367(49.1)$ \\
\hline & $\begin{array}{l}\text { Secondary education and } \\
\text { above }\end{array}$ & $39(5.2)$ \\
\hline \multirow[t]{2}{*}{ Listen to radio } & Yes & $259(34.6)$ \\
\hline & No & $489(65.4)$ \\
\hline
\end{tabular}

intracluster correlation coefficient (ICC) in the null model for skilled delivery service utilization was $61.72 \%$. In other words, $61.72 \%$ of the variation in utilization of skilled delivery care services between the WHDTs is due to the differences between the WHDTs (between-cluster variation) (Table 3).

The mixed effect modeling indicated that the individual level characters including urban residence, previous exposure of complications, at least four ANC visits and preference of skilled personnel were significantly associated with skilled delivery service utilization. For instance, women residing in urban were 35.10 times (95\% CI 4.62, 266.52) more likely to utilize skilled delivery care services as compared to their counterparts in the rural area.

Similarly, women who had four and above ANC visits were 7.44 times $(95 \%$ CI 1.48, 37.42) more likely to use skilled delivery service as compared those women who did not have any ANC follow up visits for the pregnancy of their last birth. The odds of utilizing skilled delivery service was 3.81 times $(95 \%$ CI 1.60, 9.08) more in women who experienced at least one complication during their previous pregnancies or childbirths as compared to those women who did not face any complications during their previous pregnancies or childbirth.

Among the level 2 (WHDT) variables, the distance of WHDT within $2 \mathrm{~km}$ radius from the nearest health center or hospital showed positive and significant association with skilled delivery service utilization (Table 4).

\section{Discussion}

The study showed that utilization of skilled delivery care service was well above the recent EDHS 2011 and mini EDHS 2014 reports of the country and the region, respectively $[14,24]$.

This could be due to the added number of health facilities with their appropriate health professionals and materials. Five years before the study, there were only two functioning health centers in the study area. Now, there are seven (07) health centers in different areas of the district and one district hospital at the center. Local mass media like FM radios newly opened in the area are also playing some roles in changing the attitude of the local community towards skilled maternity service utilization. All-time accessible roads might have also improved service utilization relative to the previous one.

Our analysis showed that utilization of skilled delivery care service by individual women was dependent on the joint effect of individual and group (WHDT) level factors. The ICC result indicated that the contribution of the unobserved group (WHDT) level characteristics was 
Table 2 Utilization of skilled delivery care service using selected individual and group level characteristics in Yeky district, 2015

\begin{tabular}{|c|c|c|c|}
\hline Characteristics & Category & $\mathrm{N}$ & $\begin{array}{l}\text { Number (percent) of women } \\
\text { reporting skilled delivery } \\
\text { care service use }\end{array}$ \\
\hline \multirow[t]{2}{*}{ Residence } & Urban & 116 & $111(95.7)$ \\
\hline & Rural & 632 & $223(35.3)$ \\
\hline \multirow[t]{2}{*}{ Maternal education } & Formal education & 406 & $223(54.9)$ \\
\hline & No formal education & 342 & $111(32.5)$ \\
\hline \multirow[t]{2}{*}{ Husband education } & Formal education & 527 & $260(49.3)$ \\
\hline & No formal education & 188 & $55(29.3)$ \\
\hline \multirow[t]{3}{*}{ Household monthly average income in birr } & $\leq 200$ & 448 & $145(32.4)$ \\
\hline & $201-1000$ & 217 & $118(54.4)$ \\
\hline & $>1000$ & 83 & $71(85.5)$ \\
\hline \multirow[t]{2}{*}{ Woman's autonomy in her own health care } & Woman \pm husband & 251 & $150(59.8)$ \\
\hline & Husband \pm others & 497 & $184(37)$ \\
\hline \multirow[t]{3}{*}{ ANC follow up for the last birth } & No & 83 & $7(8.4)$ \\
\hline & $1-3$ & 229 & $106(46.3)$ \\
\hline & $\geq 4$ & 436 & $221(50.7)$ \\
\hline \multirow[t]{2}{*}{ ANC in previous pregnancy } & Yes & 359 & $146(40.7)$ \\
\hline & No & 165 & $47(28.5)$ \\
\hline \multirow{2}{*}{$\begin{array}{l}\text { Ever faced complications during previous pregnan- } \\
\text { cies or childbirth }\end{array}$} & Yes & 96 & $48(50)$ \\
\hline & No & 428 & $146(34.1)$ \\
\hline \multirow[t]{2}{*}{ Women preferred skilled personnel for delivery care } & Yes & 513 & $314(61.2)$ \\
\hline & No & 235 & $20(8.5)$ \\
\hline \multirow[t]{2}{*}{ Awareness of places to get skilled providers } & Yes & 518 & $303(58.5)$ \\
\hline & No & 230 & $31(13.5)$ \\
\hline \multirow[t]{2}{*}{ Listen to radio } & Yes & 259 & $169(65.3)$ \\
\hline & No & 489 & $165(33.7)$ \\
\hline \multirow{3}{*}{$\begin{array}{l}\text { Average distance of WHDT from the nearest HF with } \\
\text { skilled care (KMs) }\end{array}$} & $\leq 2$ & 213 & $168(78.9)$ \\
\hline & $3-5$ & 230 & $80(34.8)$ \\
\hline & $>5$ & 305 & $86(28.2)$ \\
\hline \multirow[t]{2}{*}{ Self-sustained WHDT } & Yes & 592 & $280(47.3)$ \\
\hline & No & 156 & $54(34.6)$ \\
\hline \multirow[t]{4}{*}{ Performance level of WHDT } & Best performing & 302 & $128(42.4)$ \\
\hline & Good performing & 374 & $166(44.4)$ \\
\hline & Poor performing & 72 & $40(55.6)$ \\
\hline & Total & 748 & $334(44.7)$ \\
\hline
\end{tabular}

Table 3 Parameter coefficients of the intercept only (null) model in using skilled delivery care service, Yeky district, 2015

Skilled delivery care service

Level 2 variance: VAR (_cons)

$5.304^{*}(3.209,8.768)$

Intracluster correlation coefficient (Rho)

0.6172

Deviance ( -2 log likelihood)

864

* Significant

$61.72 \%$ for skilled delivery care service utilization. In the random intercept model, the between-group (WHDT) variance was significant indicating that controlling variables at different levels is important to avoid misleading associations. Past studies based on multilevel analysis indicated similar findings [29-33].

The result consistently depicted that those women who preferred skilled attendants for their delivery care were more likely to utilize skilled delivery care services than those who didn't prefer skilled attendants.

Women may get the knowledge from previous exposure of the services, through mass media, from community-based health educations or formal education.

This implicates that attitudinal changes towards seeking skilled personnel attended delivery services through repeated and multisectoral community, school and 
Table 4 Bivariate and multivariate multilevel analysis by predictors of skilled delivery care service utilization, Yeky district, 2015

\begin{tabular}{|c|c|c|c|c|}
\hline Characteristics & $\mathrm{N}$ & Crude OR $(95 \% \mathrm{Cl})$ & Adjusted OR (95\% Cl) & $P$ value (AOR) \\
\hline \multicolumn{5}{|l|}{ Individual characters } \\
\hline \multicolumn{5}{|l|}{ Residence } \\
\hline Urban & 116 & $109.44(28.70,417.29)$ & $35.10(4.62,266.52)$ & 0.001 \\
\hline Rural & 632 & 1 & 1 & \\
\hline \multicolumn{5}{|l|}{ Maternal education } \\
\hline Formal education & 406 & $2.18(1.38,3.46)$ & $1.04(0.51,2.12)$ & 0.919 \\
\hline No formal education & 342 & 1 & 1 & \\
\hline \multicolumn{5}{|l|}{ Husband education } \\
\hline Formal education & 527 & $2.17(1.27,3.69)$ & $1.29(0.61,2.75)$ & 0.503 \\
\hline No formal education & 188 & 1 & 1 & \\
\hline \multicolumn{5}{|c|}{ Woman's autonomy on her own healthcare } \\
\hline Woman \pm husband & 251 & $1.66(0.94,2.92)$ & $2.15(0.94,4.96)$ & 0.071 \\
\hline Husband \pm others & 497 & 1 & 1 & \\
\hline \multicolumn{5}{|l|}{ ANC follow up for the last birth } \\
\hline No & 83 & 1 & 1 & 0.353 \\
\hline $1-3$ & 229 & $14.42(4.55,45.74)$ & $2.22(0.41,11.90)$ & 0.015 \\
\hline$\geq 4$ & 436 & $24.05(7.76,74.52)$ & $7.44(1.48,37.42)$ & \\
\hline \multicolumn{5}{|c|}{${ }^{a}$ ANC follow up for previous pregnancy } \\
\hline Yes & 359 & $2.77(1.38,5.55)$ & $1.57(0.67,3.68)$ & 0.300 \\
\hline No & 165 & 1 & & \\
\hline \multicolumn{5}{|c|}{ Complications in previous pregnancies or births } \\
\hline Yes & 96 & $2.98(1.42,6.25)$ & $3.81(1.60,9.08)$ & 0.003 \\
\hline No & 428 & 1 & 1 & \\
\hline \multicolumn{5}{|c|}{ Skilled personnel preferred for delivery care } \\
\hline Yes & 513 & $38.37(17.03,86.43)$ & $8.11(2.61,25.15)$ & 0.000 \\
\hline No & 235 & 1 & 1 & \\
\hline \multicolumn{5}{|c|}{ Awareness of places to get skilled providers for delivery care } \\
\hline Yes & 518 & $10.41(5.68,19.07)$ & $3.00(1,9.00)$ & 0.050 \\
\hline No & 230 & 1 & 1 & \\
\hline \multicolumn{5}{|l|}{ Listen to radio } \\
\hline Yes & 259 & $3.83(2.27,6.48)$ & $0.82(0.36,1.86)$ & 0.638 \\
\hline No & 489 & 1 & 1 & \\
\hline \multicolumn{5}{|l|}{ WHDT characteristics } \\
\hline \multicolumn{5}{|c|}{ Average distance of WHDT from the nearest HF with skilled care (KMs) } \\
\hline$\leq 2$ & 213 & $15.62(7.21,33.86)$ & $6.03(1.92,18.93)$ & 0.002 \\
\hline $3-5$ & 230 & $1.46(0.76,2.81)$ & $1.34(0.54,3.31)$ & 0.522 \\
\hline$>5$ & 305 & 1 & 1 & \\
\hline \multicolumn{5}{|l|}{ Self-sustained WHDT } \\
\hline Yes & 592 & $3.27(1.16,9.16)$ & $0.74(0.24,2.29)$ & 0.603 \\
\hline No & 156 & 1 & 1 & \\
\hline \multicolumn{5}{|l|}{ The performance level of WHDT } \\
\hline Best performing & 302 & $0.58(0.20,1.69)$ & $2.14(0.38,12.27)$ & 0.391 \\
\hline Good performing & 374 & $0.89(0.32,2.51)$ & $4.38(0.75,25.56)$ & 0.101 \\
\hline Poor performing & 72 & 1 & 1 & \\
\hline \multirow[t]{3}{*}{ The random part of the model: } & VAR (cons) i.e. leve & & $2.84(1.17,6.91)$ & \\
\hline & Rho, intra-class ce & & 0.46 & \\
\hline & Deviance $(-2$ los & & 402 & \\
\hline
\end{tabular}

${ }^{a}$ Antenatal care follow-up for previous pregnancy just before the last birth 
facility-based educations could bring positive effects on skilled delivery service utilization. Our finding was consistent with other studies done elsewhere in the country $[29,34-36]$.

In the study, the association of urban residence with skilled delivery care service utilization was highly significant. This finding was in agreement with other studies done in the country and other developing countries $[2,6,16,37-44]$. This could be due to the fact that urban women tend to have better educational, economic and geographic access to health facilities and other promotional activities which are usually urban-centered.

The findings revealed that four and above times antenatal care visit was a positive and significant predictor of skilled delivery service utilization. This finding was consistent with other studies done elsewhere in the country and other sub-Saharan African Countries [2, 20, 40, 4548]. Antenatal care with skilled providers is one of the proven interventions that reduce maternal mortality by allowing early detection of obstetric complications and giving opportunity in influencing the woman's decision to utilize skilled delivery care services.

The study also revealed that women who faced any pregnancy or childbirth-related complications in previous time were more likely to seek skilled delivery care services than their counterparts.

This could also be due to the fact that women who faced complications during previous time are more complication sensitive and seek skilled care services for the fear of reoccurring of the complications. This finding is in agreement with other studies done in the country and other developing countries [11, 18, 45, 49-51].

Among the level 2 variables; the distance of WHDT from the nearest health center or hospital determines the utilization of skilled delivery service, consistent with other studies [16, 20, 22, 36, 37, 40, 49, 50, 52]. Distance from health facilities and lack of transport are important deterring factors that hinder mothers from seeking skilled maternity care services, especially delivery care.

This study revealed that there was no statistically significant association between the performance level (activities) of WHDTs and skilled delivery service utilization. This implies that it was not the performance level of WHDTs rather other factors are more relevant to explain the influences at level 2. The finding might also imply the inappropriate system of classifying, evaluating and measuring Women's Health Development Teams' performances.

\section{Conclusion}

This study revealed that about $45 \%$ of the study subjects have received skilled delivery care service. A significant heterogeneity was observed between "Women's Health
Development Teams (clusters)" for skilled delivery care service utilization. Individual-level predictors including urban residence, previous experience of pregnancy or childbirth-related complications, having four or more ANC visits for the last birth and preference of skilled personnel for care were significantly and independently associated with skilled delivery service utilization.

Although about two-thirds of the variation was explained by cluster difference, only one cluster (WHDT) level character, "distance of WHDTs from the nearest health center or hospital" was identified as the significant predictor of skilled delivery service utilization while the remaining group level characters did not show a significant association.

As a recommendation, community awareness and perception creation towards skilled personnel assisted delivery service utilization need to be enhanced. Encouraging women to have frequent ANC visits (four and above) is also important to enhance skilled delivery service utilization. More health facilities and roads need to be constructed in hard to reach areas. Telemedicine approach where communities get access to affordable on phone health care services could also be beneficial. Implementation and evaluation strategies of "Women's Health Development Army" need to be revised.

\section{Limitations}

One of the limitations of this study is the difficulty of the respondents in identifying skilled personnel between doctors, midwives, and nurses. Recalling previous events was also the other problem during data collection. Different efforts were done to reduce such errors of categorizing skilled providers and reducing recall bias. With cross-sectional study design, it could be difficult to exhaust all important determinants of skilled delivery care service utilization.

\section{Abbreviations \\ ANC: antenatal care; EDHS: Ethiopian Demographic and Health Survey; HEP: health extension program; HEW: health extension workers; ICC: intra-cluster correlation coefficient; WHDA: Women's Health Development Army; WHO: World Health Organization; WHDT: Women's Health Development Team.}

\section{Authors' contributions}

MG and YB conceived the project idea, conceptualized the design and data collection, analyzed the data and drafted the paper. AG and TL participated in the analysis and revised subsequent drafts of the paper. All authors read and approved the final manuscript.

\footnotetext{
Author details

${ }^{1}$ Department of Public Health, College of Medical and Health Sciences, Wollega University, Nekemte, Ethiopia. ${ }^{2}$ Federal Democratic Republic of Ethiopia, Ministry of Health, Addis Ababa, Ethiopia. ${ }^{3}$ Amhara National Regional State, Health Bureau, Bahirdar, Ethiopia. ${ }^{4}$ Department of Nursing, College of Health Sciences, Mizan-Tepi University, Mizan, Ethiopia.
} 


\section{Acknowledgements}

We would like to thank Dr. Eskindir Loha, Dr. Samson G/medhin, Dr. Ayalew Astatkie and Mr. Gizachew Assefa for their valuable technical supports. We would also like to thank all data collectors and study participants for their commitment and passions they had for the research. Our last but not least deep hearted gratitude goes to Mizan-Tepi University and its staffs for duplicating the questionnaires.

\section{Competing interests}

The authors declare that they have no competing interests.

\section{Availability of data and materials}

The datasets during and/or analyzed during the current study are available from the corresponding author on reasonable request.

\section{Consent for publication}

Not applicable.

\section{Ethics approval and consent to participate}

Before the beginning of our study, ethical clearance was secured from the Institutional Review Board (IRB) of Hawassa University. Permission letters were also obtained from the Zonal and District Health Offices, and Facilities before the beginning of our study. During data collection, study participants were asked for verbal consents and were informed to interrupt the interview at any time on their desire. This verbal consent had also been approved by the university's Institutional Ethical Review board ahead of the data collection. To ensure confidentiality, code numbers, instead of names were used to show results, and all questionnaires were kept locked. The privacy of the study participants was also maintained by interviewing them alone.

\section{Funding}

Self-sponsored. No external source of funding.

\section{Publisher's Note}

Springer Nature remains neutral with regard to jurisdictional claims in published maps and institutional affiliations.

Received: 2 November 2016 Accepted: 9 January 2018

Published online: 30 January 2018

\section{References}

1. Berhan Y, Berhan A. Skilled health personnel attended delivery as a proxy indicator for maternal and perinatal mortality: a systematic review. Ethiop J Health Sci. 2014:24:69-80.

2. Mengesha ZB, Biks GA, Ayele TA, Tessema GA. Determinants of skilled attendance for delivery in North West Ethiopia: a community based nested case-control study. BMC Public Health. 2013;13(130):1-6.

3. $\mathrm{WHO}, \mathrm{ICM}$, FIGO. Making pregnancy safer: the critical role of the skilled attendant. Geneva: World Health Organization; 2004. p. 1-24.

4. International Center for Research on Women. Science international center for research on women. Washington, DC: International Center for Research on Women; 2010.

5. Berhan Y, Berhan A. Causes of maternal mortality in Ethiopia. Ethiop J Health Sci. 2014;24:15-28.

6. Tarekegn MS, Lieberman SL, Giedraitis V. Determinants of maternal health service utilization in Ethiopia, analysis of 2011 EDHS. BMC Pregnancy Childbirth. 2014;14(161):1-13

7. Berhan Y, Berhan A. Review of maternal mortality in Ethiopia: a story of the past 30 years. Ethiop J Health Sci. 2014;24:3-14.

8. Berhan Y, Berhan A. Commentary: reasons for persistently high materna and perinatal mortalities in Ethiopia: part iii-perspective of the "three delays" model. Ethiop J Health Sci. 2014:24:137-48.

9. Berehan Y, Berhan A. A meta-analysis of socio-demographic factors for perinatal mortality in developing countries: a subgroup analysis of the national surveys and small-scale studies. Ethiop J Health Sci. 2014;24:41-54.
10. Mannah MT, Warren C, Kuria S, Adegoke AA. Opportunities and challenges in implementing community-based skilled birth attendance strategy in Kenya. BMC Pregnancy Childbirth. 2014;14(279):1-12.

11. Gabrysch S, Campbell OMR. Still too far to walk: the literature review of the determinants of delivery service use. BMC Pregnancy Childbirth. 2009;9(34):1-16.

12. Okigbo CC, Eke CA. Skilled birth attendance in Nigeria: a function of frequency and content of antenatal care. Afr J Reprod Health. 2015;19(1):25-33.

13. WHO, UNICEF, UNFPA, World Bank, United Nations Population Division. Trends in maternal mortality: 1990-2013. Geneva: WHO; 2014. p. 1-68.

14. Central Statistical Agency [Ethiopia] and ICF International: Ethiopia Demographic and Health Survey. Addis Ababa, Ethiopia, and Calverton, Maryland. USA: Central Statistical Agency and ICF International; 2011. p. 2012.

15. International monetary fund: 2014 article IV consultaton-staff report; press release; and the statement by the executive director for the Federal Democratic Republic of Ethiopia. 2014 Contract No.: IMF Country Report No. $14 / 303 ; 2014$

16. Tey NP, Lai SL. Correlates of and barriers to the utilization of health services for delivery in South Asia and sub-Saharan Africa. Sci World J. 2013;2013:1-11.

17. Woldie M. The death of the mother and her child keeps on bothering developing nations. Ethiop J Health Sci. 2014;24:1-2.

18. Tsegay Y, Gebrehiwot T, Goicolea I, Edin K, Lemma H, Sebastian SM. Determinants of antenatal care and delivery care utilization in Tigray Region, Ethiopia: a cross-sectional study. Int J Equity Health. 2013;12(30):1-10.

19. Birmeta K, Dibaba Y, Woldeyohannes D. Determinants of maternal health care utilization in Holeta town, Central Ethiopia. BMC Health Serv Res. 2013;13(256):1-9.

20. Moyer CA, Mustafa A. Drivers and deterrents of facility delivery in subSaharan Africa: a systematic review. Reprod Health. 2013;10(40):1-14.

21. Esena RK, Sappor MM. Factors associated with the utilization of skilled delivery services in the GA East Municipality of Ghana. Int J Sci Technol Res. 2013;2(8):184-94.

22. Mpembeni NMR, Killewo ZJ, Leshabari TM, Massawe NS, Jahn A, Mushi D, et al. Use pattern of maternal health services and determinants of skilled care during delivery in Southern Tanzania: implications for achievements of MDG 5 Targets. BMC Pregnancy Childbirth. 2007;7(29):1-7.

23. Sibley LM, Sipe TA, Barry D. Traditional birth attendant training for improving health behaviors and pregnancy outcomes. Cochrane Database Syst Rev. 2012:8:1-70. https://doi.org/10.1002/14651858.CD005460.pub3.

24. Central Statistical Agency [Ethiopia]: Ethiopia Mini Demographic and Health Survey 2014. Addis Ababa, Ethiopia: Central Statistical Agency [Ethiopia]; 2014

25. Federal Democratic Republic of Ethiopia: Ministry of Health. Policy and practice: information for action. Addis Ababa: The Federal Democratic Republic of Ethiopia, Ministry of Health; 2013. p. 1-62.

26. Federal Democratic Republic of Ethiopia: Ministry of Health. Policy and practice: information for action. Addis Ababa: The Federal Democratic Republic of Ethiopia, Ministry of Health; 2014. p. 1-58.

27. Teklehaimanot HD, Teklehaimanot A. Human resource development for a community-based health extension program: a case study from Ethiopia. Hum Resour Health. 2013;11(39):1-12.

28. USAID, Health Systems 2020. Health Extension Program: an innovative solution to public health challenges of Ethiopia: a case study. USAID 2012; p. 1-12.

29. Worku AG, Yalew AW, Afework MF. Factors affecting utilization of skilled maternal care in North West Ethiopia: a multilevel analysis. BMC Int Health Hum Rights. 2013;13(20):1-11.

30. Stella B, Adesegun F. Determinants of use of maternal health services in Nigeria-looking beyond individual and household factors. BMC Pregnancy Childbirth. 2009;9(43):1-13

31. Debelew GT, Afework MF, Yalew AW. Factors affecting birth preparedness and complication readiness in Jimma Zone, Southwest Ethiopia: a multilevel analysis. Pan Afr Med J. 2014:19(272):1-14.

32. Sepheri A, Sarma S, Simpson W, Moshiri S. How important are individual, household and commune characteristics in explaining utilization of maternal health services in Vietnam? Soc Sci Med. 2008;67:1009-17. 
33. Tsui A, Ukwuani F, Guilkey D, Angeles G. A comparative multi-level analysis of health program effects on individual use of reproductive and sexual health services. Meas Eval Bull. 2003;6:1-12.

34. Yohannes B, Tarekegn M, Paulos W. Mothers' utilization of antenatal care And their satisfaction with delivery services in selected public health facilities of Wolaita Zone, Southern Ethiopia. Int J Sci Technol Res. 2013;2(2):1-12.

35. Hailu M, Gebremariam A, Alemseged F, Deribe K. Birth preparedness and complication readiness among pregnant women in Southern Ethiopia. PloS ONE. 2011;6(6):e21432. https://doi.org/10.1371/journal. pone.0021432

36. Shiferaw S, Spigt M, Godefrooij M, Melkamu Y, Tekie M. Why do women prefer home births in Ethiopia? BMC Pregnancy Childbirth. 2013;13(5):1-10.

37. Berhan Y, Berhan A. A meta-analysis of socio-demographic factors predicting birth in health facility. Ethiop J Health Sci. 2014;24:81-92.

38. Muchabaiwa L, Mazambani D, Chigusiwa L, Bindu S, Mudavanhu V. Determinants of maternal healthcare utilization in Zimbabwe. Int J Econ Sci Appl Res. 2012;5(2):145-62.

39. Zere E, Tumusiime P, Walker O, Kirigia J, Mwikisa C, Mbeeli T. Inequalities in utilization of maternal health interventions in Namibia: implications for progress towards MDG 5 targets. Int J Equity Health. 2010;9(16):1-11.

40. Shrestha KS, Banu B, Khanom K, Ali L, Thapa N, Stray-Pedersen B, et al. Changing trends on the place of delivery: why do Nepali women gave birth at home? Reprod Health. 2012;9(25):1-7.

41. Dagne E. Role of socio-demographic factors on utilization of maternal health care services in Ethiopia. 2010; 1-36.

42. Abebe F, Berhane Y, Girma B. Factors associated with home delivery in Bahirdar, Ethiopia: a case-control study. BMC Res Notes. 2012;5(653):1-7.

43. Amano A, Gebeyehu A, Birhanu Z. Institutional delivery service utilization in Munisa Woreda, South East Ethiopia: a community-based cross-sectional study. BMC Pregnancy Childbirth. 2012;12(105):1-6.
44. Fekadu M, Regassa N. Skilled delivery care service utilization in Ethiopia: analysis of rural-urban differentials based on national demographic and health survey (DHS) data. Afr Health Sci. 2014;14(4):974-84.

45. Berhan Y, Berhan A. Antenatal care as a means of increasing birth in the health facility and reducing maternal mortality. Ethiop J Health Sci. 2014;24:93-104.

46. Bloom SS, Lippeveld T, Wypij D. Does antenatal care make a difference to safe delivery? A study in urban Uttar Pradesh, India. Health Policy Plan. 1999;14(1):38-48.

47. Hagos S, Shaweno D, Assegid M, Mekonnen A, Afework FM, Ahmed S. Utilization of institutional delivery service at Wukro and Butajera districts in the Northern and South Central Ethiopia. BMC Pregnancy Childbirth. 2014;14(178):1-11.

48. Feyissa TR, Genemo GA. Determinants of institutional delivery among childbearing age women in Western Ethiopia, 2013: unmatched casecontrol study. PLoS ONE. 2014;9(5):1-7.

49. Titaley RC, Hunter LC, Dibley JM, Heywood P. Why do some women still prefer traditional birth attendants and home delivery?: a qualitative study on delivery care services in West Java Province, Indonesia. BMC Pregnancy Childbirth. 2010;10(43):1-14.

50. Anyait A, Mukanga D, Oundo BG, Nuwaha F. Predictors for health facility delivery in Busia district of Uganda: a cross-sectional study. BMC Pregnancy Childbirth. 2012;12(132):1-9.

51. Worku AG, Yalew AW, Afework MF. Maternal complications and women's behavior in seeking care from skilled providers in North Gondar, Ethiopia. PLOS ONE. 2013;8(3):1-8.

52. Phiri SN, Fylkesnes K, Ruano AL, Moland KM. 'Born before arrival': user and provider perspectives on health facility childbirths in Kapiri Mposhi district. Zambia. BMC Pregnancy Childbirth. 2014;14(323):1-9.

\section{Submit your next manuscript to BioMed Central and we will help you at every step:}

- We accept pre-submission inquiries

- Our selector tool helps you to find the most relevant journal

- We provide round the clock customer support

- Convenient online submission

- Thorough peer review

- Inclusion in PubMed and all major indexing services

- Maximum visibility for your research

Submit your manuscript at www.biomedcentral.com/submit
() BioMed Central 